\title{
Identification of Genes Potentially Involved in the Biocontrol Activity of Pseudozyma flocculosa
}

\author{
G. Marchand, W. Rémus-Borel, F. Chain, W. Hammami, F. Belzile, and R. R. Bélanger
}

First, second, third, fourth, and sixth authors: Département de Phytologie, Centre de recherche en horticulture, Pavillon de l'Envirotron, and fifth author: Département de Phytologie, Pavillon C. E.-Marchand, Université Laval, Québec, Québec, G1V 0A6, Canada.

Accepted for publication 1 May 2009.

\begin{abstract}
Marchand, G., Rémus-Borel, W., Chain, F., Hammami, W., Belzile, F., and Bélanger, R. R. 2009. Identification of genes potentially involved in the biocontrol activity of Pseudozyma flocculosa. Phytopathology 99:1142-1149.

Flocculosin is an antifungal cellobiose lipid linked to the biocontrol activity of Pseudozyma flocculosa and whose structure is very similar to that of ustilagic acid produced by Ustilago maydis. In this work, homologs of the $U$. maydis cypl gene, involved in the biosynthesis of ustilagic acid, were isolated and sequenced from $P$. flocculosa and $P$. fusiformata, the latter species being also known to produce ustilagic acid. Interestingly, no homologs were found in four other closely related

gene was partially sequenced from $P$. flocculosa. All three newly sequenced genes showed strong sequence similarity to their counterparts in U. maydis. Cypl expression was monitored in conditions that were either conducive or repressive to flocculosin production. Expression increased markedly $(>100 x)$ when $P$. flocculosa was inoculated in a growth medium conducive to flocculosin production but was rapidly downregulated in a repressive medium (in vitro) or on powdery mildewinfected cucumber leaves (in vivo). This suggests that the molecule was preferentially synthesized early in the process of searching for a growth substrate. This study provides the first identification of genes involved in the production of flocculosin, a molecule potentially associated with the biocontrol properties of $P$. flocculosa.
\end{abstract} Pseudozyma spp. from which no evidence of ustilagic acid production has ever been obtained, thus supporting the specificity of cypl with ustilagic acid synthesis. In addition, a homolog of the $U$. maydis uatl gene involved in the acetylation of the molecule and located next to the cyp 1
Additional keywords: biocontrol agent, gene expression, quantitative reverse-transcription PCR.
Pseudozyma flocculosa (Traquair, L. A. Shaw \& Jarvis) Boekhout \& Traquair (syn.: Sporothrix flocculosa) is a biocontrol agent (BCA) with particular activity against powdery mildews. This yeast-like epiphyte was first described as an ascomycete (26) and later reclassified as a basidiomycete related to anamorphs of the Ustilaginales $(3,6)$. The intrinsic biocontrol properties of $P$. flocculosa have led to the study of its mode of action against powdery mildews. From the very beginning, it was evident that $P$. flocculosa was neither a strong competitor in the phyllosphere nor a direct hyperparasite, and that direct contact between the biocontrol agent and target powdery mildew was not required (10). Powdery mildew cells exposed to $P$. flocculosa were plasmolyzed rapidly and, thus, antibiosis was proposed as the main mode of action (9). Isolation and characterization of active compounds were then instigated $(2,4,5,11)$, which led to the discovery of flocculosin (7). This molecule, an unusual glycolipid with strong antimicrobial activity (17), is believed to be a key factor in the biocontrol properties of $P$. flocculosa.

In an effort to identify genes involved in the biocontrol activity (or flocculosin synthesis) of $P$. flocculosa, random insertional mutagenesis was attempted (7). Even though mutants altered in their antagonistic properties and flocculosin production were obtained, genetic analysis of insertions remained inconclusive due to the high number of tandem insertions.

One breakthrough in efforts to understand the role of flocculosin in the biocontrol activity of $P$. flocculosa came from

Corresponding author: R. R. Bélanger;

E-mail address: richard.belanger@plg.ulaval.ca

doi:10.1094/PHYTO-99-10-1142

(C) 2009 The American Phytopathological Society the discovery that its chemical structure was nearly identical to that of ustilagic acid produced by the model plant pathogen Ustilago maydis (DC.) Corda (Fig. 1). U. maydis is one of the first fungal pathogens to be sequenced and its complete genome is now publicly available (14). Using a reverse genetics approach, Hewald et al. (13) identified a gene essential for the production of ustilagic acid. This gene, cypl, codes for a putative P450 monooxygenase that is believed to catalyze the terminal hydroxylation of hexadecanoic acid to generate the rare 15-16-dihydroxy palmitic acid, the essential precursor for ustilagic acid biosynthesis, and, thus, would be the first active enzyme in the biochemical pathway for ustilagic acid synthesis (24). Expression studies of genes located near cypl revealed a cluster of coregulated genes involved in ustilagic acid synthesis, including uatl, located downstream of cypl and believed to code for an acyl/acetyltransferase involved in acetylation of ustilagic acid.

Given that $P$. flocculosa and $U$. maydis are very closely related genetically and given that flocculosin and ustilagic acid share the same unusual chemical structure, we surmised that the production of flocculosin in $P$. flocculosa must share a common biochemical pathway with that of ustilagic acid in $U$. maydis. If this hypothesis holds true, this could lead to the identification of genes involved in flocculosin synthesis and, by extension, to the biocontrol activity of $P$. flocculosa. In addition, considering that another species of Pseudozyma, P. fusiformata (Buhagiar) Boekhout, also produces ustilagic acid (15), we were interested in assessing the genetic basis for synthesis of these unusual molecules by screening other species within the genus. Accordingly, the objective of this study was to search for homologs of $U$. maydis genes involved in ustilagic acid synthesis in related Pseudozyma spp., as well as to monitor expression of key genes in the biosynthetic pathway should a homolog be found in the 
BCA $P$. flocculosa in conditions of flocculosin production and biocontrol activity.

\section{MATERIALS AND METHODS}

Fungal material. $P$. flocculosa (CBS 167.88) and U. maydis (DSM 4500) were maintained on potato dextrose agar (PDA) at $4^{\circ} \mathrm{C}$. In addition, $P$. fusiformata, reported to produce ustilagic acid, and four other Pseudozyma spp. presumed not to produce the molecule-P. rugulosa (Traquair, L. A. Shaw \& Jarvis) Boekhout \& Traquair (CBS 170.88), P. antarctica (Goto, Sugiyama \& Iizuka) Boekhout (CBS 516.83), P. tsukubaënsis (Onishi) Boekhout (CBS 6389), and P. aphidis (Henninger \& Windisch) Boekhout (CBS 517.83) —were tested for the presence of the cypl gene and maintained under the same conditions. Unless indicted otherwise, fungi were cultured in YMPD broth. All culture media ingredients were supplied by Difco (BD Biosciences, Mississauga, Ontario, Canada). Podosphaera xanthii (Castagne) U. Braun \& Shishkoff was grown and maintained on cucumber plants (cv. Corona) in a greenhouse as described by Neveu et al. (19).

Culture conditions for cyp1 gene expression analysis and flocculosin production experiments. Primary cultures of $\mathrm{Pseu}$ dozyma flocculosa were obtained by inoculating $100 \mathrm{ml}$ of YMPD broth in a 500-ml baffled flask with one bottle of lyophilized culture previously hydrated with $3 \mathrm{ml}$ of sterile water. Seed cultures were prepared in triplicate by adding $5 \mathrm{ml}$ of a 3-day-old primary culture to either $100 \mathrm{ml}$ of YMPD broth repressive to flocculosin production or $100 \mathrm{ml}$ of buffered basic culture medium (MOD medium) (12) conducive to flocculosin production. Two $1-\mathrm{ml}$ aliquots were taken at $0,4,8,12$, and $24 \mathrm{~h}$ after inoculation in repressive conditions and at $0,4,8,12,24,48,72$, 96 , and $120 \mathrm{~h}$ after inoculation in conducive conditions. The first 1 -ml aliquot was centrifuged at 3,000 $\times g$ for $15 \mathrm{~min}$, the supernatant was removed, and cells were frozen in liquid nitrogen until RNA extraction. The second 1-ml aliquot was used to quantify flocculosin production.

For the experiment on infected cucumber leaf disks, primary cultures of $P$. flocculosa were prepared as previously described. After centrifugation, cells were resuspended in saline $(\mathrm{NaCl}$ $0.9 \%$ ) and cell titer was adjusted to $5 \times 10^{6}$ cells $/ \mathrm{ml}$ with a hemacytometer. As described by Neveu et al. (19), the cell suspension was then sprayed evenly over 20-mm discs excised from leaves of cucumber plants infected with Podosphaera xanthii. The treated leaf discs were placed in petri dishes, which were sealed with parafilm and incubated in a growth chamber with a photoperiod of $16 \mathrm{~h}$ at 22 to $20^{\circ} \mathrm{C}$ with a photosynthetic photon flux of $\approx 275 \mu \mathrm{mol} / \mathrm{m}^{2} \mathrm{~s}$ as described by Hajlaoui and Bélanger (9). Three foliar discs were harvested at $0,2,4,6,24,48,72$, and $96 \mathrm{~h}$ after being sprayed with the fungal suspension. Individual discs were placed in microtubes, frozen in liquid nitrogen, and then stored at $-80^{\circ} \mathrm{C}$ until RNA extraction.

DNA and RNA extraction. Fungal genomic DNA was isolated from 3- to 5-day-old cultures in potato dextrose broth using the Genomic Tip 20/G or 100/G kits (Qiagen, Mississauga, Ontario, Canada). Total RNA was isolated from the fungal biomass of Pseudozyma flocculosa and $P$. fusiformata grown in flocculosinconducive MOD medium (12) and from infected cucumber leaf discs inoculated with $P$. flocculosa using Trizol reagent (Invitrogen, Carlsbad, CA) following the manufacturer's instructions. Bacteriophage DNA was isolated as described by Santos (22) based on phage precipitation with zinc chloride.

Southern blot analysis of the cyp1 gene in Pseudozyma spp. Genomic DNA $(10 \mu \mathrm{g})$ was digested with BamHI, separated electrophoretically on a $1 \%$ agarose gel, and transferred onto Hybond N+ nylon membrane (Amersham Biosciences UK Ltd., Little Chalfont Bucks, UK) using a VacuGene XL vacuum blotting system (Amersham) according to the manufacturer's instructions. The open reading frame (ORF) of the cloned $U$. maydis cypl gene (donated by M. Bölker, Universitaet Marburg, Germany) was labeled with ${ }^{32} \mathrm{P}$ using the Rediprime II random prime labeling system (Amersham); hybridized to the Southern blot overnight at $65^{\circ} \mathrm{C}$ in $2 \times \mathrm{SSC}(1 \times \mathrm{SSC}$ is $0.15 \mathrm{M} \mathrm{NaCl}$ plus $0.015 \mathrm{M}$ sodium citrate), $0.25 \%$ dry milk, and $0.5 \%$ sodium dodecyl sulfate (SDS); and washed at $65^{\circ} \mathrm{C}$ in $2 \times \mathrm{SSC}$ and $0.1 \%$ SDS.

Construction of a $\boldsymbol{P}$. flocculosa genomic DNA library. As described by Neveu et al. (18), a $P$. flocculosa genomic DNA library was constructed using BamHI-digested genomic DNA in the lambda Fix-II replacement vector (Stratagene, La Jolla, CA) following the manufacturer's protocol. For screening of this library, plate lifts were performed on Hybond N+ nylon membrane (Amersham) according to the manufacturer's instructions. The cloned $U$. maydis cypl gene ORF was used as a probe as above. A lambda clone containing a $15-\mathrm{kb}$ insert was selected for sequencing. This clone was digested with SacI and SalI and restriction fragments were subcloned in pBluescript II $\mathrm{KS}(+)$ (Stratagene) and sequenced using an ABIPrism 3130XL sequencer (Applied Biosystems, Foster City, CA).

Northern transfer and hybridization. Total RNA (3 $\mu \mathrm{g})$ extracted from $P$. flocculosa grown in MOD medium conducive to flocculosin production was separated elecrophoretically on a $1 \%$ (wt/vol) agarose gel containing 5.4\% formaldehyde in MOPS $1 \times$ buffer. Total RNA was transferred onto Hybond $\mathrm{N}+$ nylon membrane as above. A 412-bp polymerase chain reaction (PCR) product of the $P$. flocculosa cypl gene obtained with primers 5'ACGGCTACGGCAACACGC-3' and 5'-GGCTGGTCGGGCTTGGAG-3' was labeled and hybridized to membranes as above.

Primer extension. To map the transcription start site, nonradioactive automated primer extension analysis was used as described by Altermann et al. (1). Extension reactions were carried out with 9 pmol primer (5'-CCCAGAAGAGGTTGCCGAGC-3', with IRD700 at the 5' end) annealed to $1 \mu \mathrm{g}$ of total RNA isolated from $P$. flocculosa. Reference sequencing reactions

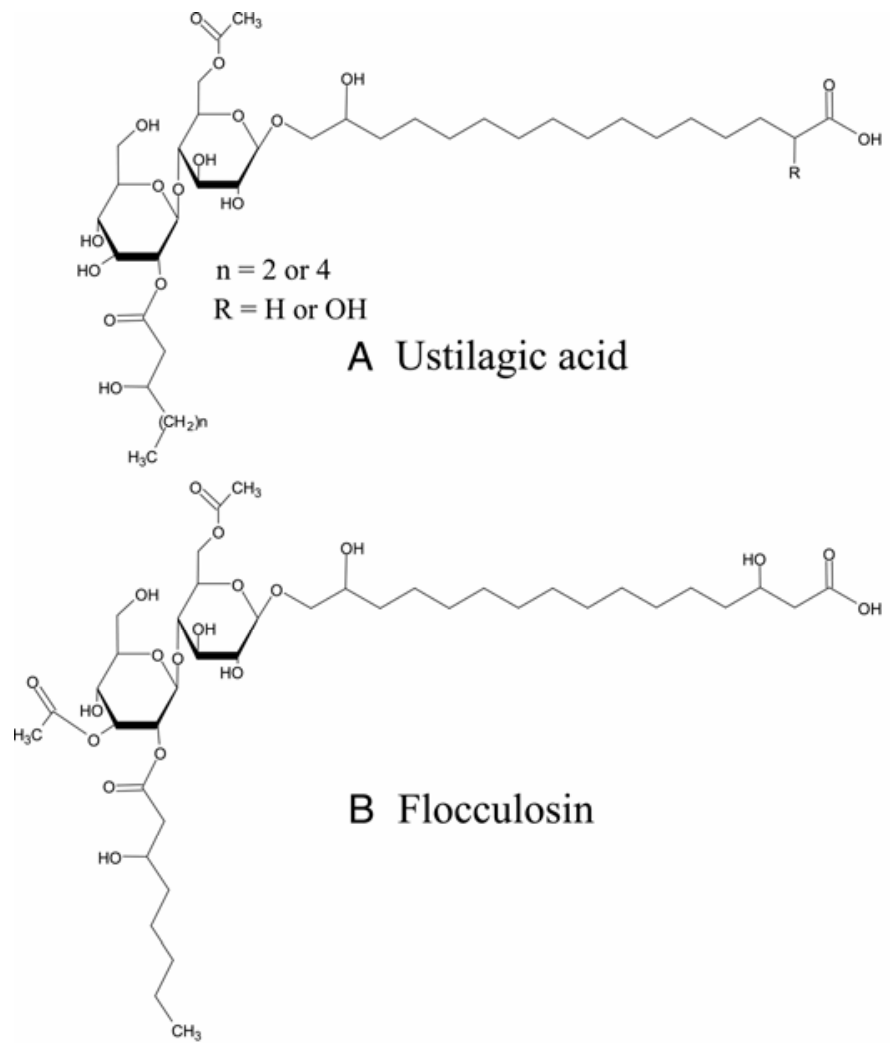

Fig. 1. Chemical structures of $\mathbf{A}$, ustilagic acid and $\mathbf{B}$, flocculosin. 
were initiated using the same primer on a SalI genomic subclone using a primer-labeled cycle sequencing kit (LI-COR, Lincoln, $\mathrm{NE}$ ). Products of the primer extension and sequencing reactions were separated on a 4200L IR2 system DNA sequencer (LI-COR).

$3^{\prime}$ Rapid amplification of cDNA ends on the $P$. flocculosa cyp1 transcript. 3' Rapid amplification of cDNA ends (RACE) PCR was performed as follows: oligo-dT-adaptor-primer 5'-GGAATCAGTCAGTAATTGGAGGTTTTTTTTTTTTTTTTTT-3' was used for first-strand cDNA synthesis using SuperScriptIII reverse transcriptase (Invitrogen) on $1.5 \mu \mathrm{g}$ of total RNA. Second-round amplification was performed with adaptor-primer 5'-GGAATCAGTCAGTAATTGGAGG-3' and gene-specific primer 5'-GACGCAGGTCATCAACTCG-3' using Phusion DNA polymerase (Finnzymes, Espoo, Finland), yielding a PCR product of $\approx 440 \mathrm{bp}$ that was gel purified using the QIAquick gel extraction kit (Qiagen) and sequenced.

Phylogenetic analysis. To further establish whether the putative $P$. flocculosa cyp 1 gene was a functional homolog of the $U$. maydis cypl gene, the amino acid sequence of $P$. flocculosa cypl transcript was submitted to the National Center for Biotechnology Information (NCBI) Position-Specific Iterated Basic Local Alignment Search Tool (PSI-BLAST) using a nonredundant protein sequence database (nr). The multiple sequence alignment was obtained using ClustalW software (25). A neighbor-joining phylogenetic tree was then constructed using the MEGA software version 4.1 (23) based on the previously obtained alignment of amino acid sequences. Reliability of internal nodes was assessed using 1,000 bootstraps and the amino acid scoring matrix Jones-Taylor-Thornton (JTT) was used to calculate the evolutionary distance between each sequence pair.

PCR-based cloning of partial sequences of the $\boldsymbol{P}$. fusiformata cyp1 gene. Degenerate primers 5'-AGAAGTACGGNTACGG-3' and 5'-CCATGGCCCAGTCCGANTAGAG-3' were designed using consensus regions in the alignment between the $P$. flocculosa and $U$. maydis cypl genomic sequences, and used to amplify a fragment of $\approx 1,100 \mathrm{bp}$ of the $P$. fusiformata cypl gene from genomic DNA, yielding 1,033 bp of sequence data. The 3' RACE PCR reactions were performed as follows: oligo-dT-adaptor-primer 5'-GGAATCAGTCAGTAATTGGAGGTTTTTTTTTTTTTTTTTT-3' was used for first-strand cDNA synthesis using SuperScriptIII reverse transcriptase (Invitrogen) on $1.5 \mu \mathrm{g}$ of total RNA. Second-round amplification was per-

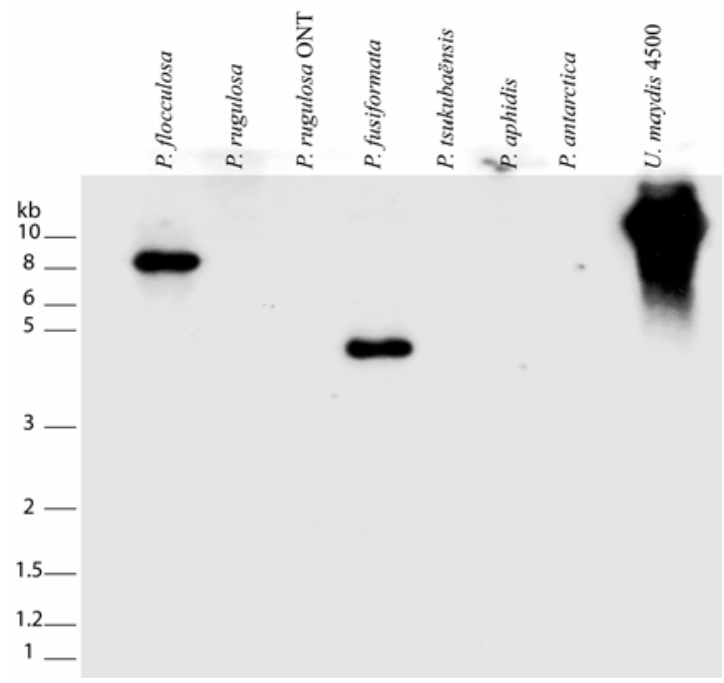

Fig. 2. Southern transfer of BamHI-digested genomic DNA from Pseudozyma spp. and hybridization with the ${ }^{32} \mathrm{P}$-labeled Ustilago maydis cloned cypl open reading frame probe. Genomic DNA from $U$. maydis was used as a positive control. Pseudozyma flocculosa: CBS 167.99, P. rugulosa and $P$. rugulosa ONT: CBS 170.88, P. fusiformata: CBS 6951, P. tsukubaënsis: CBS 6389, P. aphidis: CBS 517.83, P. antarctica: CBS 516.83, and U. maydis: DSM 4500. formed with adaptor-primer 5'-GGAATCAGTCAGTAATTGGAGG-3' and gene-specific primer 5'-GTTGGCGGACGATGTTCTGC-3' using HotMaster DNA polymerase (Eppendorf), yielding a PCR product of $\approx 530$ bp that was cloned into the pGEM-T easy vector (Promega Corp., Madison, WI) and sequenced.

Quantitative reverse-transcription PCR analysis of cyp1 expression. Differential expression of $P$. flocculosa cypl was assessed by quantitative (q)PCR using a Mastercycler EP Realplex 2S (Eppendorf). Total RNA was extracted from fungal biomass grown in media either conducive (MOD) or repressive (YMPD) to flocculosin production, or from infected cucumber leaf discs using $1 \mathrm{ml}$ of Trizol reagent (Invitrogen) and then quantified using a Nanodrop spectrophotometer (Nanodrop, Delaware). For each of the three biological replicates, $1 \mu \mathrm{g}$ of total RNA was first treated with RQ1 RNase-free DNase (Promega Corp.) and then reverse transcribed into first-strand cDNA using OligodT(18) and Superscript II reverse transcriptase (Invitrogen) in a 20- $\mu \mathrm{l}$ reaction volume. Primer pairs for selected genes were designed with Oligo Explorer software (Genelink) in order to amplify 100- to 150-bp fragments with similar GC and Tm and were as follows: P. flocculosa actin (20): 5'-TCTGCTTCGAGACCTTCAAC-3' and 5'-GAGTAGCCCTCGTAGATGG-3' and $P$. flocculosa cypl: 5'-TGTCAAGATCGCCTTTAGCC-3' and 5'-CGGTCTCGTTGTACTTTTCG-3'. PCR amplifications were performed in a $20-\mu$ l reaction volume using the Quantitect SYBR green PCR kit (Qiagen) with $1 \mu$ of sample cDNA. PCR was performed as follows: $15 \mathrm{~min}$ at $95^{\circ} \mathrm{C}$ plus 50 cycles of $20 \mathrm{~s}$ at $95^{\circ} \mathrm{C}, 20 \mathrm{~s}$ at $58^{\circ} \mathrm{C}$, and $20 \mathrm{~s}$ at $72^{\circ} \mathrm{C}$. Each sample from each biological replicate was analyzed twice. The specificity of primer pairs was verified both by gel and melting curve analysis. The $P$. flocculosa actin gene was used as an internal control for normalization. Efficiencies of all primer pairs used were determined and the quantification of the relative changes in gene expression was performed using the Pfaffl method (21).

Measurement of flocculosin concentration. Quantification of flocculosin was carried out as described by Hammami et al. (12). Briefly, each 1-ml aliquot of liquid culture of $P$. flocculosa was centrifuged at $10,000 \times g$ for $5 \mathrm{~min}$. The supernatants were removed and $1 \mathrm{ml}$ of $\mathrm{CH}_{3} \mathrm{OH}$ was added to the pellets. Tubes were vortexed and centrifuged at $10,000 \times g$ for an additional 5 min. Supernatants were kept at $-20^{\circ} \mathrm{C}$ prior to high-performance liquid chromatography (HPLC) analysis. An HPLC (Agilent, 1100 series) coupled with an ELSD detector (Sedere, Sedex 75, France) was used for flocculosin quantification. Flocculosin was eluted on a C8 column (ZORBAX, Eclipse XDB-C8; 4.6-by-150 $\mathrm{mm}$ ) with the following linear gradient: $40: 60 \mathrm{CH}_{3} \mathrm{OH} /$ water to $80: 20 \mathrm{CH}_{3} \mathrm{OH} /$ water at a flow rate of $0.8 \mathrm{ml} / \mathrm{min}$ for $20 \mathrm{~min}$. Under these conditions, flocculosin was eluted at $\approx 13 \mathrm{~min}$.

Sequence deposition. Sequence data have been deposited in GenBank under the following accession numbers: $P$. flocculosa cyp1 and partial uat1: EU556541, partial P. fusiformata cyp1: EU553488.

\section{RESULTS}

Southern blot analysis of the cyp1 gene in Pseudozyma spp. Given our interest in understanding the relationship between glycolipid production and antibiosis in related Pseudozyma spp., we attempted to screen different species with known or reported properties for glycolipid production (or lack thereof) for the presence of cypl gene homologs using the $U$. maydis ORF as probe (Fig. 2). Among the seven strains of the six Pseudozyma spp. tested, a signal was detected only in lanes corresponding to $P$. flocculosa and P. fusiformata genomic DNA. In both species, a single Bam $\mathrm{HI}$ fragment was observed as in the $U$. maydis-positive control, suggesting that the putative cypl gene homolog is present in a single copy. 
Sequencing of a $\boldsymbol{P}$. flocculosa genomic clone. A $P$. flocculosa genomic DNA library was screened with the $U$. maydis cypl probe. Among several positive clones, one was selected for sequencing. Sequenced subclones revealed an ORF showing strong sequence similarity ( $70 \%$ identity) to the U. maydis CYP1 protein (Fig. 3). Fortuitously, sequencing of genomic plasmid subclones from the lambda clone identified using the $U$. maydis cypl probe revealed the presence of another partial ORF $(1,076$ nucleotides [nt]) at the extremity of the $15-\mathrm{kb}$ genomic insert. When the sequence was compared against the $U$. maydis database (14), this partial ORF showed sequence similarity (88\% identity) to the $U$. maydis uatl gene $(1,542 \mathrm{nt})$, located next to cypl and coding for an acyl/acetyltransferase believed to be involved in acetylation and possibly also acylation of ustilagic acid (24).

Molecular characterization of cyp1 gene. In order to further characterize the putative cypl gene in P. flocculosa, total RNA was extracted from the fungus grown in a medium conducive to flocculosin production (MOD). Following a Northern blot analysis with a fragment of the native cypl gene used as a probe, a predominant band of $\approx 2.2 \mathrm{~kb}$ was detected (Fig. 4). Primer extension indicated a transcription initiation site located $74 \mathrm{bp}$ upstream of the start codon in the $P$. flocculosa cypl gene homolog, and no alternative transcription initiation site was detected (Fig. 5). The 3' RACE yielded a 3' untranslated region (UTR) of $212 \mathrm{nt}$. Thus, the predicted ORF (1,602 nt) along with the two UTRs $(74+212 \mathrm{nt})$ and the polyA tail corresponds well with the $\approx 2.2-\mathrm{kb}$ band observed in the Northern analysis. Analysis of the ORF indicates that the predicted P. flocculosa CYP1 protein (534 amino acids [aa]) is missing 148 aa relative to the $\mathrm{N}$ terminal portion of the U. maydis CYP1 protein (Fig. 3).

PCR-based cloning of partial sequences of the $P$. fusiformata cyp1 gene and phylogenetic analysis. A partial sequence of a cypl gene homolog was amplified from $P$. fusiformata using degenerate primers based on an alignment of the DNA sequences of the putative $P$. flocculosa and $U$. maydis cypl genes, followed by $3^{\prime}$ RACE on cDNA. This putative $P$. fusiformata cypl gene showed strong sequence similarity $(88 \%$ identity with $U$. maydis cypl) to homologs in U. maydis and P. flocculosa (Fig. 3).

When comparing the amino acid sequence of the $P$. flocculosa putative CYP1 protein to that of other fungi or plants found in the
NCBI databank, the search indicated that all retrieved sequences shared a conserved domain typical of the P450 superfamily, and most of these were annotated as cytochrome P450 monooxygenases. This conserved domain extended approximately between residues 180 and 630 of the $U$. maydis sequence. Among the obtained sequences, the phylogenetic tree revealed a tight and specific clustering between the CYP1 protein of $U$. maydis and its nearest homologs found in P. fusiformata and P. flocculosa (Fig. 6).

Quantitative reverse-transcription PCR analysis of cyp1 expression and flocculosin production. The expression of cypl was assessed in situ through quantitative reverse-transcription (qRT)-PCR. First, the expression of cypl was compared in $P$. flocculosa cultures grown in a medium conducive (MOD medium) or repressive (YMPD medium) to flocculosin production. In conducive conditions, expression of the cypl gene increased rapidly and was closely associated with the accumulation of flocculosin in the medium (Fig. 7). At the end of the sampling period, the expression of cypl decreased while flocculosin accumulation started to stabilize. In repressive conditions, both the expression of cypl and the concentration of flocculosin were undetected over the sampling period (data not shown).

When expression of the cypl gene was monitored following the inoculation of $P$. flocculosa on powdery mildew-infected cucum-

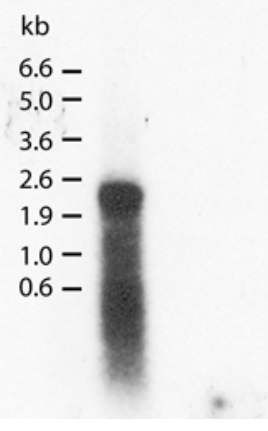

Fig. 4. Northern transfer of total RNA from Pseudozyma flocculosa and hybridization with the ${ }^{32} \mathrm{P}$-labeled Ustilago maydis cloned cyp1 open reading frame probe.

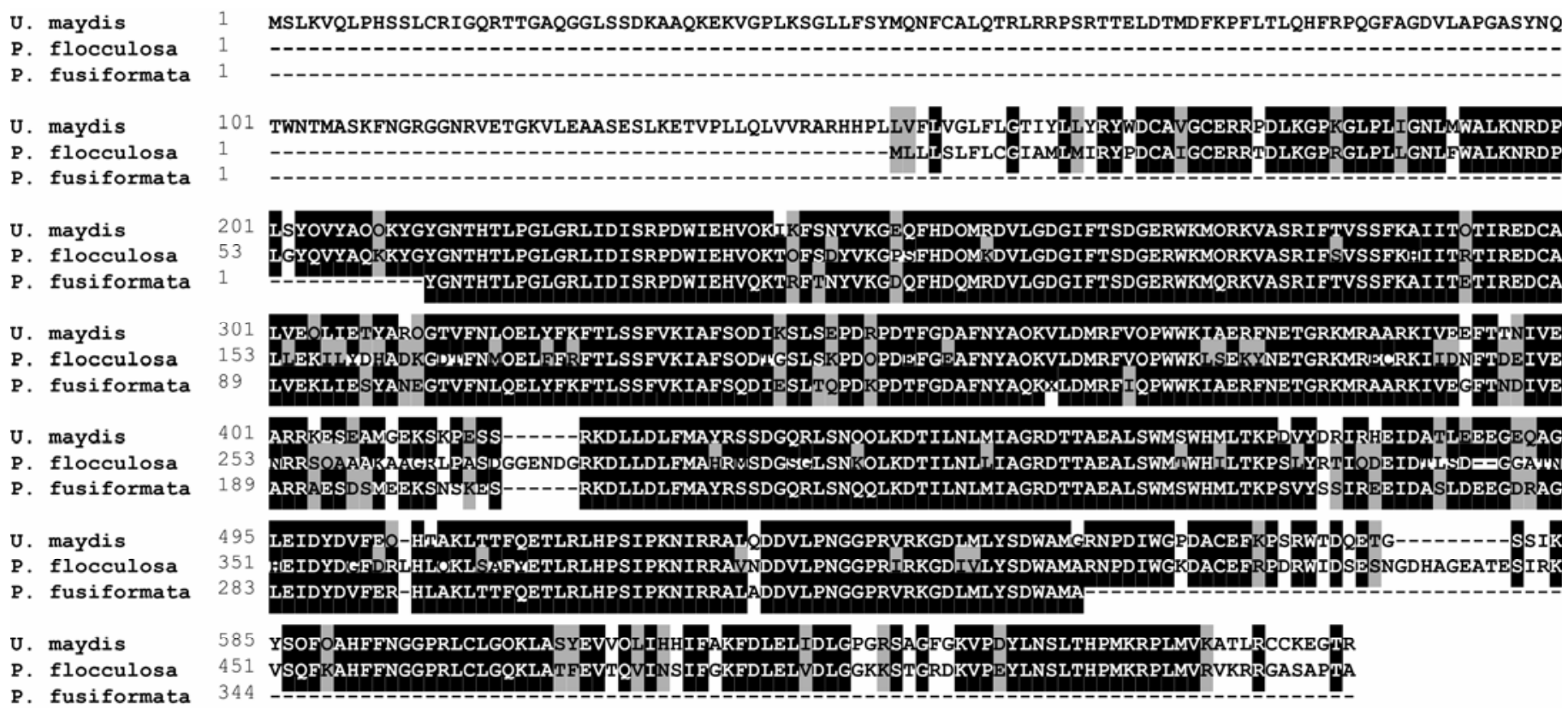

Fig. 3. Sequence alignment of the putative Pseudozyma flocculosa CYP1 protein (EU556541), partial P. fusiformata CYP1 predicted proteins (EU553488), and the Ustilago maydis CYP1 protein (UM06463.1). GenBank accession numbers are between parentheses. The alignment was performed using the ClustalW application. Similar and identical amino acid residues are shadowed in gray and black, respectively. 
ber leaves, it decreased rapidly (Fig. 8) as the fungus expanded over the powdery mildew colonies.

\section{DISCUSSION}

Considering the number of fungal BCAs identified in the literature, there is very little information about potential genes that confer, even partially, an antagonistic activity to such fungi. In this work, we report on the identification and the study of expression of genes in the powdery mildew BCA $P$. flocculosa that present characteristics consistent with the production of the antifungal glycolipid flocculosin, associated with the biocontrol properties of the fungus.

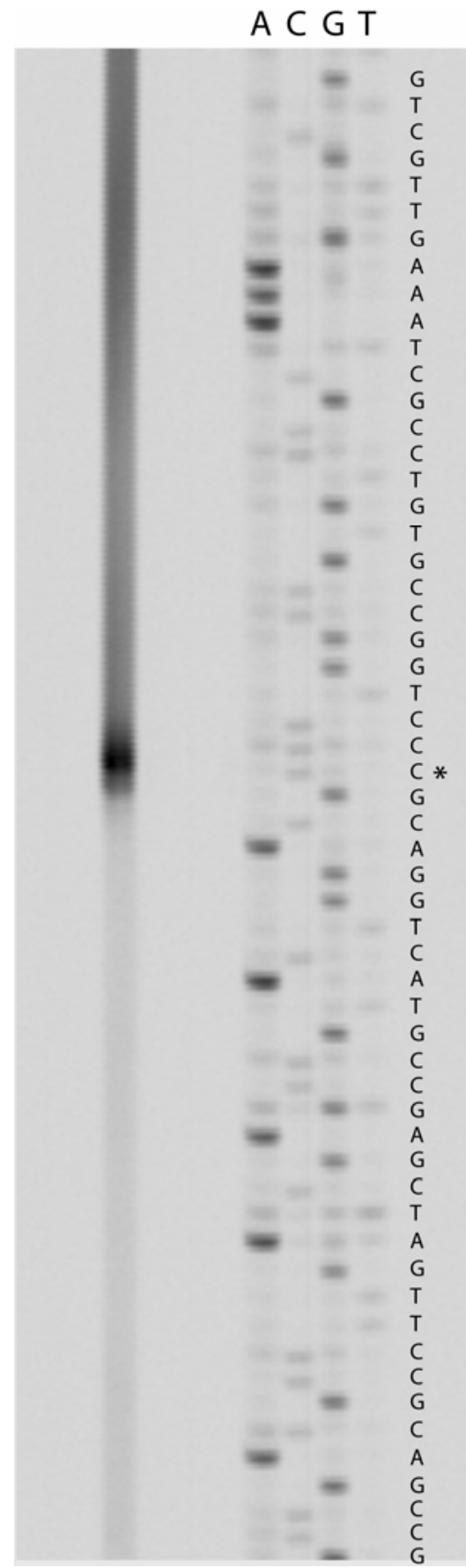

Fig. 5. Mapping of cypl transcript from Pseudozyma flocculosa by nonradioactive automated primer extension. Lanes A, C, G, and T correspond to the reference sequencing reactions. The sequence of the coding strand encompassing the $3^{\prime}$ end of the extension product is shown to the right, with an asterisk marking the transcription initiation site.
Our results revealed that homologs of the $U$. maydis cypl gene, a putative $\mathrm{P} 450$ monooxygenase involved in ustilagic acid synthesis in $U$. maydis, could be found in only two of the six species of Pseudozyma tested, P. flocculosa and P. fusiformata. Although this may seem surprising from a phylogenetic point of view, it is biologically relevant because these are the only two species reported to produce cellobiose-type lipids similar to ustilagic acid $(7,15,17)$. Thus, this observation supports the proposed functional tie and specificity between the cypl gene and the production of ustilagic acids (including flocculosin). It also indicates that the other species of Pseudozyma have either lost the need for the production of ustilagic acid, such that the gene sequence has been lost or is free to mutate and diverge considerably over the course of evolution, or simply never carried the gene. Considering that the Pseudozyma genus has been recently created from an aggregate of more or less disparate species $(3,6)$, the latter hypothesis seems more probable. The apparent absence of a close homolog of cypl (based on the results of the Southern analysis) is consistent with the loss or absence of such homologs in species known not to produce ustilagic acids. Finally, the finding that a single copy of the gene was present in $P$. flocculosa and $P$. fusiformata suggests that the cloned sequences are truly orthologous to the $U$. maydis cypl gene.

Another argument which ties the function of the cypl gene from $U$. maydis with that of the putative cypl cloned from $P$. flocculosa and $P$. fusiformata is the tight clustering of these sequences observed in the phylogenetic tree. All three sequences shared a common node, with robust bootstrap values indicating that these proteins share a close genetic and functional relatedness compared with other $\mathrm{P} 450$ proteins. This supports their specific role in the unique ability of those three fungi to synthesize ustilagic acids.

Three other putative P450 monooxygenases were found in $U$. maydis (UM01863, UM01723, and UM06473) but were located on other nodes, suggesting that these proteins are closer to other P450 sequences than to CYP1. If there was another P450 monooxygenase in $P$. flocculosa more closely related to the $U$. maydis cypl gene, it would likely have been detected in the Southern analysis.

In spite of their relatedness, an intriguing difference between the $U$. maydis and $P$. flocculosa CYP1 proteins is the additional 148 aa reported in the $\mathrm{N}$ terminus of the former (13). Based on our sequence alignment, it appears that $U$. maydis would be exceptional in this regard because all the other proteins lacked this segment.

Although identification of a cypl homolog in P. flocculosa was the central objective of this work, we stumbled upon a partial sequence of the P. flocculosa uatl gene from the genomic clone containing the cypl gene. This finding could have important implications because these two genes are also positioned next to each other in the $U$. maydis genome. Incidentally, Teichman et al. (24) reported that $U$. maydis contained a gene cluster with 12 ORFs that probably accounted for all the enzymes necessary for ustilagic acid synthesis. With their model system, the latter group was able to ascertain the role of some ORFs in ustilagic acid synthesis by mutational analysis. For our part, we have been unable to apply the same approach with cypl in $P$. flocculosa, because only a low number of transformants have been obtained in our attempts to generate a cypl deletion mutant by gene knockout via homologous recombination (16). Thus, whether the same cluster exists in $P$. flocculosa or $P$. fusiformata still remains to be determined but our results do support this possibility. It would then be interesting to determine whether the small structural differences between flocculosin and ustilagic acid can be explained by the presence of a few different ORFs within the cluster.

If ustilagic acids appear to be produced by only a few ustilagineous fungi, it is unclear, based on the reported ecology of 
these fungi, what role, if any, the molecule plays in their respective ecological fitness. The creation of specific $\Delta c y p 1 P$. flocculosa mutant strains would undoubtedly prove very useful in assessing with precision the role of flocculosin in biocontrol but this approach is currently hampered by our inability to transform the fungus via homologous recombination as explained earlier. However, by measuring cypl expression by qPCR in controlled conditions, we were able to shed some light on its possible role, and to gather additional evidence linking it to the production of flocculosin in P. flocculosa. For instance, it was clear that cyp 1

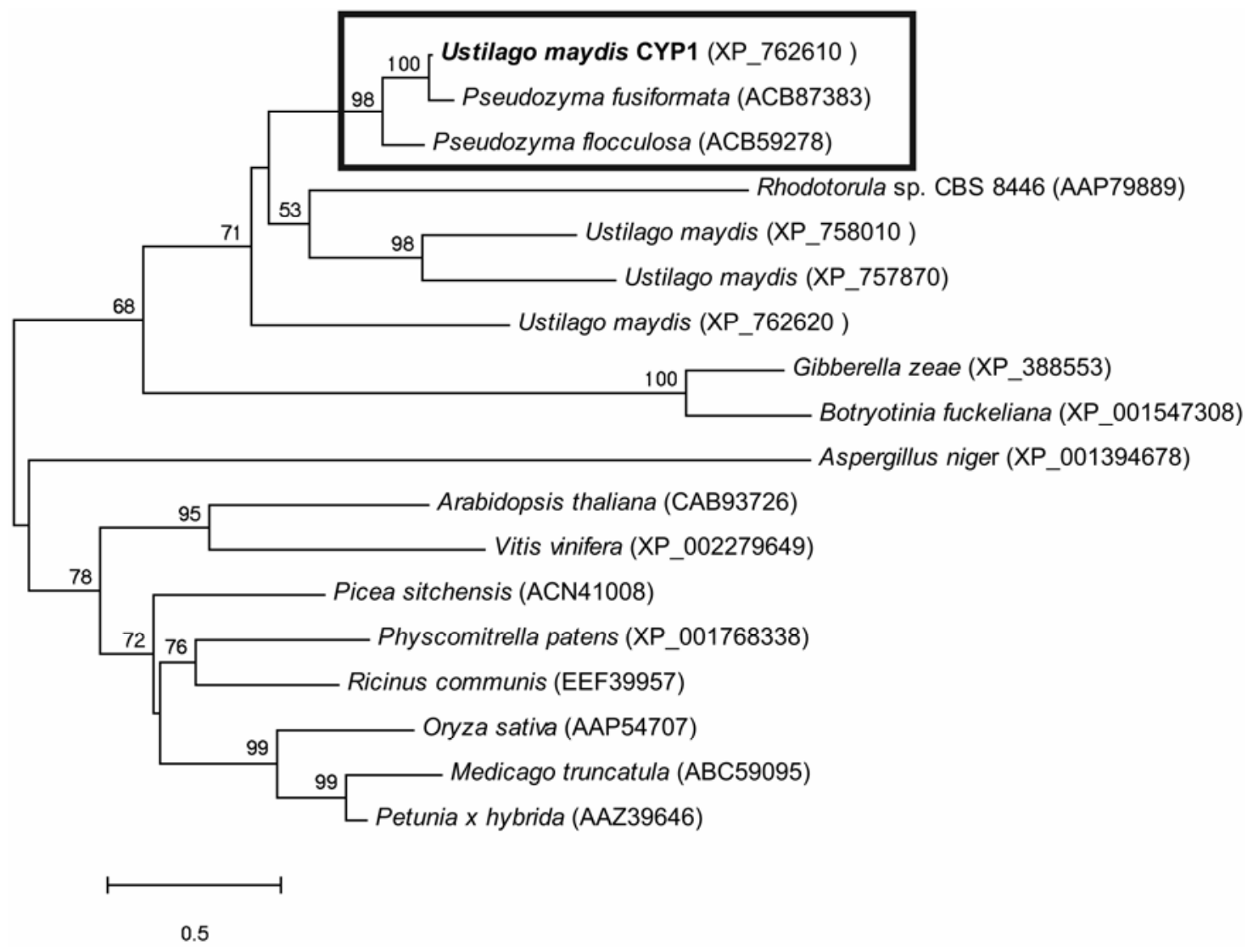

Fig. 6. Unrooted phylogenetic tree of cytochrome P450 monooxygenases from various plants and fungi. Sequences were obtained from a BLASTp search using the putative Pseudozyma flocculosa CYP1 protein as query. Accession number for each amino acid sequence is indicated in parentheses. The numbers on the branches are the percentage values based on 1,000 bootstraps. Only bootstrap values $>50 \%$ are shown. The bar represents 0.5 estimated amino acid change per sequence position.

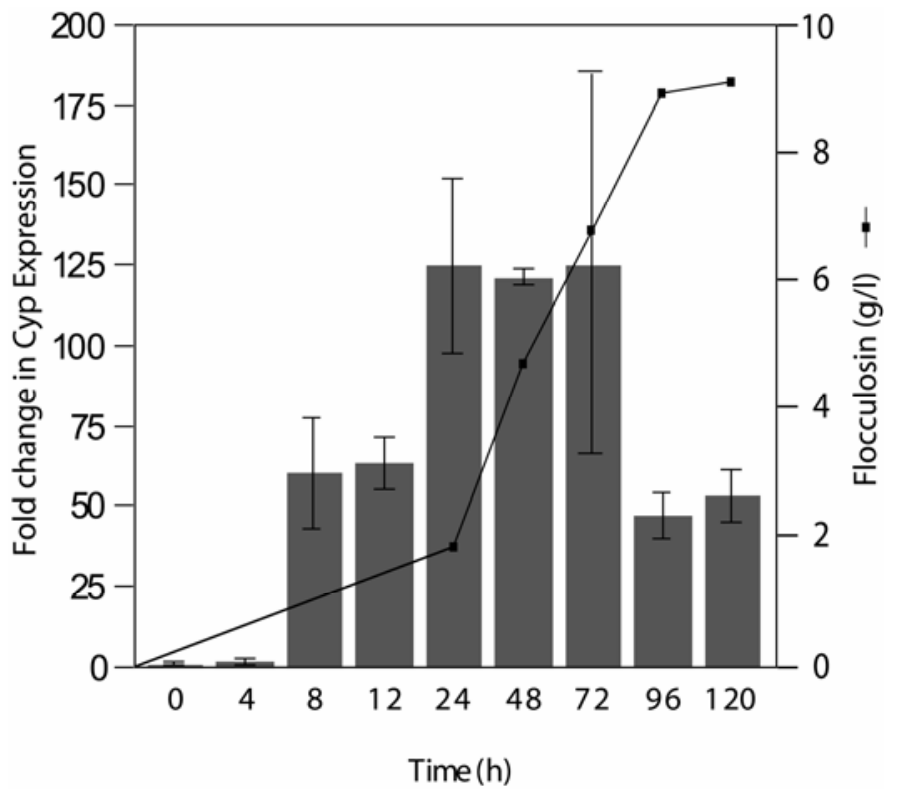

Fig. 7. Quantitative reverse-transcription polymerase chain reaction analysis of Pseudozyma flocculosa actin-normalized cyp1 expression and flocculosin quantification within a growth medium conducive to flocculosin production. Error bars represent the standard error for each treatment.

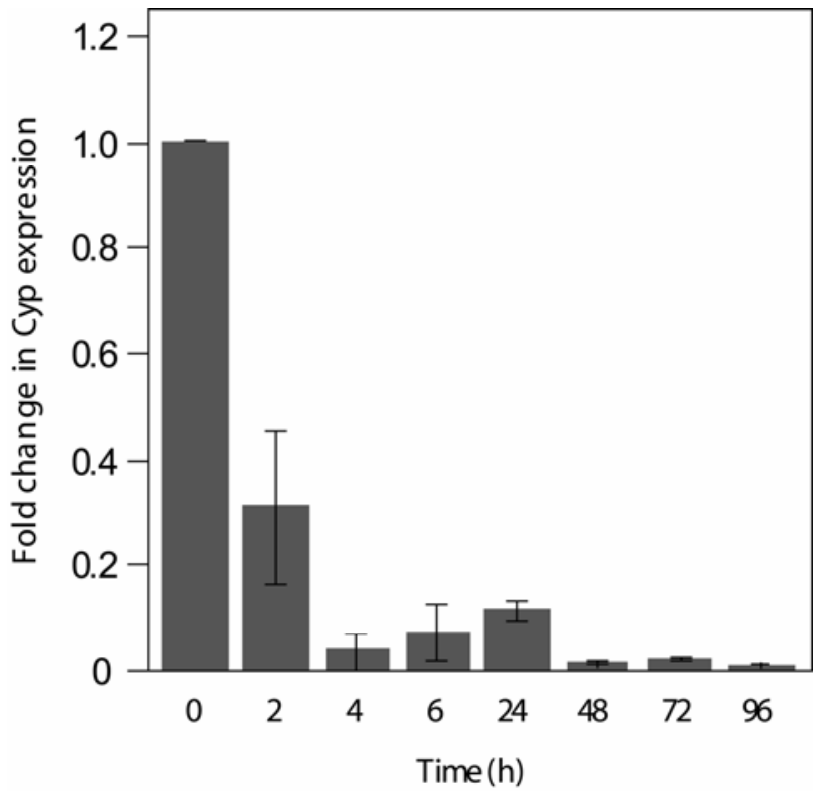

Fig. 8. Quantitative reverse-transcription polymerase chain reaction analysis of Pseudozyma flocculosa actin-normalized cypl expression after inundative applications of conidia on powdery mildew-infected cucumber leaf discs. Error bars represent the standard error for each treatment. 
expression was closely associated with the production of flocculosin in culture media under conditions conducive or repressive to its synthesis. Based on this observation, our qRTPCR results of cypl expression on infected cucumber suggest that flocculosin production is not synchronized, or strictly inherent, to the development of $P$. flocculosa on powdery mildew. This is in agreement with a recent report by Clément-Mathieu et al. (8), who found that, even if $P$. flocculosa possesses the ability to induce collapse of powdery mildews when sharing the same environment, its biocontrol activity, if modulated by flocculosin, is highly dependent on other factors stimulating its ability to develop and grow in the presence of powdery mildew colonies. Indeed, in the presence of powdery mildew, cypl expression would be quickly downregulated because $P$. flocculosa expands rapidly on the pathogen colonies, a process similar to the rapid biomass development in a culture medium, conditions shown here and previously (12) to be repressive to flocculosin production. It may seem counterintuitive that the studied gene was downregulated in the presence of the target plant pathogen, but this relates to our knowledge of the ecology of P. flocculosa. An interesting parallel can also be drawn from the reported production of ustilagic acid by $U$. maydis. It has been hypothesized that anamorphs of the pathogen produce ustilagic acid as they search for a sporidium of a compatible mating type. It is likely that the infectious dikaryon then formed does not need to produce ustilagic acid in order to infect the plant, because knockout mutants of cypl showed no alteration in pathogenicity (13). Furthermore, Teichmann et al. (24) demonstrated the antagonistic activity of ustilagic acid against Botrytis cinerea. Therefore, it is very plausible that this antagonistic activity helps protect the ecological niche of the haploid sporidia awaiting their compatible mating type in the same way that flocculosin protects the ecological niche of $P$. flocculosa against would-be invaders such as powdery mildews.

In conclusion, this study provides the identification of two genes, cypl and uatl, along with transcriptional studies of cypl that support its involvement in the production of flocculosin, a molecule associated with the biocontrol properties of $P$. flocculosa. A homolog of cypl was also discovered in the closely related fungus $P$. fusiformata, known to produce ustilagic acid. Both these genes share considerable sequence similarity with those found in the gene cluster responsible for ustilagic acid production in the plant pathogen $U$. maydis. Although both $P$. flocculosa and $U$. maydis are phylogenetically related, they have evolved different ecological roles that seem nonetheless enhanced in similar ways by the production of their respective glycolipid.

\section{ACKNOWLEDGMENTS}

We thank M. Bölker for providing the cloned U. maydis cypl ORF sequence, S. Laberge and D. Gagné for their help with the primer extension reactions, J. Laroche from the Bioinformatics and Computational Biology Center (Laval University) for his help with the phylogenetic analysis, and C. Labbé for technical assistance with the figures. This work was supported by grants from Fonds Québécois de la Recherche sur la Nature et les Technologies (FQRNT), the Natural Sciences and Engineering Research Council of Canada (NSERC), and the Canada Research Chairs Program to R. R. Bélanger.

\section{LITERATURE CITED}

1. Altermann, E., Klein, J. R., and Henrich, B. 1999. Synthesis and automated detection of fluorescently labelled primer extension products. Biotechniques 26:98-101.

2. Avis, T. J., Boulanger, R. R., and Bélanger, R. R. 2000. Synthesis and biological characterization of (Z)-9-heptadecenoic and (Z)-6-methyl-9heptadecenoic acids: fatty acids with antibiotic activity produced by Pseudozyma flocculosa. J. Chem. Ecol. 26:987-1000.

3. Begerow, D., Bauer, R., and Boekhout, T. 2000. Phylogenetic placements of ustilaginomycetous anamorphs as deduced from nuclear LSU rDNA sequences. Mycol. Res. 104:53-60.

4. Benyagoub, M., Rhlid, R. B., and Bélanger, R. R. 1996. Purification and characterization of new fatty acids with antibiotic activity produced by Sporothrix flocculosa. J. Chem. Ecol. 22:405-413.

5. Benyagoub, M., Willemot, C., and Bélanger, R. R. 1996. Influence of a subinhibitory dose of antifungal fatty acids from Sporothrix flocculosa on cellular lipid composition in fungi. Lipids 31:1077-1082.

6. Boekhout, T. 1995. Pseudozyma Bandoni emend. Boekhout, a genus for yeast-like anamorphs of Ustilaginales. J. Gen. Appl. Microbiol. 41:359366.

7. Cheng, Y. L., McNally, D. J., Labbe, C., Voyer, N., Belzile, F., and Bélanger, R. R. 2003. Insertional mutagenesis of a fungal biocontrol agent led to discovery of a rare cellobiose lipid with antifungal activity. Appl. Environ. Microbiol. 69:2595-2602.

8. Clément-Mathieu, G., Chain, F., Marchand, G., and Bélanger, R. R. 2008. Leaf and powdery mildew colonization by glycolipid-producing Pseudozyma species. Fungal Ecology, doi:10.1016/j.funeco.2008.09.003

9. Hajlaoui, M. R., and Bélanger, R. R. 1993. Antagonism of the yeast-like phylloplane fungus Sporothrix flocculosa against Erysiphe graminis var. tritici. Biocontrol Sci. Technol. 3:427-434.

10. Hajlaoui, M. R., Benhamou, N., and Bélanger, R. R. 1992. Cytochemical study of the antagonistic activity of Sporothrix flocculosa on rose powdery mildew, Sphaerotheca pannosa var. rosae. Phytopathology 82:583-589.

11. Hajlaoui, M. R., Traquair, J. A., Jarvis, W. R., and Bélanger, R. R. 1994. Antifungal activity of extracellular metabolites produced by Sporothrix flocculosa. Biocontrol Sci. Technol. 4:229-237.

12. Hammami, W., Labbé, C., Chain, F., Mimee, B., and Bélanger, R. R. 2008. Nutritional regulation and kinetics of flocculosin synthesis by Pseudozyma flocculosa. Appl. Microbiol. Biotechnol. 80(2):307-315.

13. Hewald, S., Josephs, K., and Bolker, M. 2005. Genetic analysis of biosurfactant production in Ustilago maydis. Appl. Environ. Microbiol. 71:3033-3040.

14. Kamper, J., Kahmann, R., Bolker, M., Ma, L.-J., Brefort, T., Saville, B. J., Banuett, F., Kronstad, J. W., Gold, S. E., Mueller, O., Perlin, M. H., Wosten, H. A. B., de Vries, R., Ruiz-Herrera, J., Reynaga-Pena, C. G., Snetselaar, K., McCann, M., Perez-Martin, J., Feldbruegge, M., Basse, C. W., Steinberg, G., Ibeas, J. I., Holloman, W., Guzman, P., Farman, M., Stajich, J. E., Sentandreu, R., Gonzalez-Prieto, J. M., Kennell, J. C., Molina, L., Schirawski, J., Mendoza-Mendoza, A., Greilinger, D., Munch, K., Rossel, N., Scherer, M., Vranes, M., Ladendorf, O., Vincon, V., Fuchs, U., Sandrock, B., Meng, S., Ho, E. C. H., Cahill, M. J., Boyce, K. J., Klose, J., Klosterman, S. J., Deelstra, H. J., Ortiz-Castellanos, L., Li, W., Sanchez-Alonso, P., Schreier, P. H., Haeuser-Hahn, I., Vaupel, M., Koopmann, E., Friedrich, G., Voss, H., Schluter, T., Margolis, J., Platt, D., Swimmer, C., Gnirke, A., Chen, F., Vysotskaia, V., Mannhaupt, G., Gueldener, U., Munsterkotter, M., Haase, D., Oesterheld, M., Mewes, H.-W., Mauceli, E. W., DeCaprio, D., Wade, C. M., Butler, J., Young, S., Jaffe, D. B., Calvo, S., Nusbaum, C., Galagan, J., and Birren, B. W. 2006. Insights from the genome of the biotrophic fungal plant pathogen Ustilago maydis. Nature 444:97-101.

15. Kulakovskaya, T. V., Shashkov, A. S., Kulakovskaya, E. V., and Golubev, W. I. 2005. Ustilagic acid secretion by Pseudozyma fusiformata strains. FEMS Yeast Res. 5:919-923.

16. Marchand, G. 2008. Étude des déterminants génétiques de l'antibiose de Pseudozyma flocculosa, un agent de lutte biologique. Thèse de doctorat, Département de phytologie, Faculté des sciences de l'agriculture et de l'alimentation, Université Laval, Québec.

17. Mimee, B., Labbé, B., Pelletier, R., and Bélanger, R. R. 2005. Antifungal activity of flocculosin, a novel glycolipid isolated from Pseudozyma flocculosa. Antimicrob. Agents Chemother. 49:1597-1599.

18. Neveu, B., Belzile, F., and Bélanger, R. R. 2007. Cloning of the glyceraldehyde-3-phosphate dehydrogenase gene from Pseudozyma flocculosa and functionality of its promoter in two Pseudozyma species. Antonie Leeuwenhoek G. 92:245-255.

19. Neveu, B., Labbé, C., and Bélanger, R. R. 2007. GFP technology for the study of biocontrol agents in tritrophic interactions: a case study with Pseudozyma flocculosa. J. Microbiol. Methods 68:275-281.

20. Neveu, B., Michaud, M., Belzile, F., and Bélanger, R. R. 2007. The Pseudozyma flocculosa actin promoter allows the strong expression of a recombinant protein in the Pseudozyma species. Appl. Microbiol. Biotechnol. 74:1300-1307.

21. Pfaffl, M. W., Horgan, G. W., and Dempfle, L. 2002. Relative expression software tool (REST (c)) for group-wise comparison and statistical analysis of relative expression results in real-time PCR. Nucleic Acids Res. 30:e36.

22. Santos, M. A. 1991. An improved method for the small-scale preparation of bacteriophage DNA based on phage precipitation by zinc-chloride. Nucleic Acids Res. 19:5442-5442.

23. Tamura, K., Dudley, J., Nei, M., and Kumar, S. 2007. MEGA4: Molecular 
evolutionary genetics analysis (MEGA) software version 4.0. Mol. Biol. Evol. 24:1596-1599.

24. Teichmann, B., Linne, U., Hewald, S., Marahiel, M. A., and Bolker, M. 2007. A biosynthetic gene cluster for a secreted cellobiose lipid with antifungal activity from Ustilago maydis. Mol. Microbiol. 66:525533.
25. Thompson, J. D., Higgins, D. G., and Gibson, T. J. 1994. CLUSTAL W: improving the sensitivity of progressive multiple sequence alignment through sequence weighting, position-specific gap penalties and weight matrix choice. Nucleic Acids Res. 22:4673-4680.

26. Traquair, J. A., Shaw, L. A., and Jarvis, W. R. 1988. New species of Stephanoascus with Sporothrix anamorphs. Can. J. Bot. 66:926-933. 